\title{
REPORT OF THE CARBON IN OCEANS WORKSHOP, SUNDAY 14 AUGUST 1994
}

\author{
ANN P. MCNICHOL \\ National Ocean Sciences Accelerator Mass Spectrometer Facility, Department of Marine Geology \\ and Geophysics, Woods Hole Oceanographic Institution, Woods Hole, Massachusetts 02543 USA
}

The use of radiocarbon to understand the modern carbon cycle was the primary focus of this workshop. More than half the talks reported work from studies of seawater-dissolved inorganic carbon (DIC). Reidar Nydal showed an impressive summary of his work describing the history of the penetration of the bomb ${ }^{14} \mathrm{C}$ pulse into the surface ocean water. He summarized all the data he has collected in the atmosphere and from surface ocean water between $45^{\circ} \mathrm{N}$ and S. Recent work in his laboratory has focused in the Northern Seas, and Jorunn Gislefoss demonstrated the seasonal cycle in $\mathrm{CO}_{2}$ and $\delta^{13} \mathrm{C}$ at one station. A large seasonal signal in these parameters is evident at the surface (2 $\mathrm{m}$ deep), which is damped and not evident deeper in the water column (600 and $2000 \mathrm{~m}$ ).

Tsung-Hung Peng and Wally Broecker then discussed their revised inventory of pre-bomb radiocarbon in the ocean and the techniques they used to arrive at the new estimate. They used three methods to estimate the pre-bomb levels of radiocarbon in the surface ocean, actual measurements on historical shells and corals, correlations with the tritium penetration depth, and use of the oceanic $\Delta^{14} \mathrm{C} / \mathrm{dis}$ solved $\mathrm{SiO}_{2}$ relation. The results they presented came from the analysis of Geochemical Ocean-Section Study (GEOSECS) radiocarbon data. Their revised inventory is $290-330 \times 10^{26}{ }^{14} \mathrm{C}$ atoms, a value still greater than that presented by others, e.g., Hesshaimer, Heinmann and Levin (1994). It was evident that further discussion was required of what parameters should be studied in order to bring these estimates into better agreement.

Peng and Christoph Heinze both presented their $\Delta^{14} \mathrm{C} v s$. $\mathrm{SiO}_{2}$ relations, which were used to calculate "pre-bomb" radiocarbon in the surface oceans. The calculated slopes agree to within 10\%o, approximately the uncertainty in the calculated values. The use of this relationship to calculate pre-bomb surface ocean radiocarbon values is not intuitive. It assumes ${ }^{14} \mathrm{C}$ in the ocean as a whole decays at a constant rate and that $\mathrm{SiO}_{2}$ dissolves homogeneously. Heinze used the Hamburg ocean carbon cycle model and GEOSECS data to test the relationship he had derived and calculated expected $\Delta^{14} \mathrm{C}$ values at $25 \mathrm{~m}$. At present, the model can predict only to within $\pm 10-30 \%$, with some areas off by as much as $70 \%$. Future modifications to the model should bring them into better agreement. It also seems apparent that measurements of actual pre-bomb surface $\Delta^{14} \mathrm{C}$ using museum collection shells should help constrain these relations and models. Bob Key presented some of the first World Ocean Circulation Experiment (WOCE) radiocarbon data from the Northeast Pacific; his results were from large-volume samples collected in waters deeper than $1000 \mathrm{~m}$. He presented detailed contours for constant density surfaces and discussed preliminary model calculations. Key's work made it clear that there is a real interest in and need for the WOCE AMS radiocarbon data to be processed and made available as soon as possible.

After these presentations, the conference moved to other studies using radiocarbon in different reservoirs to study carbon cycling. John Jiricowic presented work that will lead toward coupling "wiggle-matching" techniques with data from Arctica islandica, a high-latitude clam shell, to calibrate the oceanic radiocarbon scale. The project is in its infancy, but has the potential to provide calibration for ocean surface waters back to $6000 \mathrm{yr}$. Ellen Druffel presented data from suspended particulate organic carbon (POC) collected seasonally from a site near the southern California coast. Suspended POC is collected with an in-situ filtration device; it is not actively sinking. The major feature seen in the $\Delta^{14} \mathrm{C}$ of the suspended POC pool was a decrease of $c a .160 \%$ o from surface to bottom, 
which requires upiake of old carbon by this carbon pool. A study of organic classes in the sinking POC (collected using sediment traps) showed differences and seasonality in the $\Delta^{14} \mathrm{C}$ of organic compound classes. There was the suggestion that the lipid class originated from a different source than the rest of the organic matter. Ann McNichol presented a preliminary study coupling $\delta^{13} \mathrm{C}$ and $\Delta^{14} \mathrm{C}$ from sediment pore water DIC to estimate the oxidation of recent organic matter within sediments. Results suggest that, in nearshore sediments, $75-90 \%$ of carbon added to pore water is modern, but that in deep-sea sediments, there is little indication of oxidation of recent material. Finally, Tim Eglinton described the method he is developing using preparative capillary gas chromatography to isolate relatively large $(20-100 \mu \mathrm{g})$ quantities of individual organic compounds from natural matrices. Preliminary results using a few different natural materials indicate it can be applied with great success. These last four studies point to the need to reduce even further the sample size required to obtain high-precision analyses. Many AMS labs are working toward this goal.

\section{REFERENCE}

Hesshaimer, V., Heimann, M. and Levin, I. 1994 Radiocarbon evidence for a smaller oceanic carbon dioxide sink than previously believed. Nature 370: 201-203. 